\title{
Health care trends in Brazil and other Latin American countries
}

\section{M.B. Ferraz}

\section{Correspondence \\ M.B. Ferraz \\ Divisão de Reumatologia \\ Departamento de Medicina \\ Escola Paulista de Medicina \\ UNIFESP \\ Rua Botucatu, 685 \\ 04023-062 São Paulo, SP \\ Brasil \\ Fax: 55 (011) 575-6427 \\ E-mail:marcos.ferraz@fleury.com.br \\ Publication supported by FAPESP. \\ $\ldots \ldots \ldots \ldots \ldots \ldots \ldots \ldots \ldots$}

Received October 22, 1997

Accepted December 11, 1997
Divisão de Reumatologia, Departamento de Medicina, Escola Paulista de Medicina, Universidade Federal de São Paulo, São Paulo, SP, Brasil
Brazil, as many other countries in the world, is facing the challenge of implementing programs for the more efficient delivery of health care services. Since resources are scarce and limited and in view of the constant advance of health care technology, it is important to evaluate which preventive, diagnostic and therapeutic interventions add value to the health care system; in other words, the interventions that more efficiently improve human health. It is interesting to point out that in Brazil as in other countries in Latin America, as expected, health care reform cannot be dissociated from other economic and political changes that are occurring almost simultaneously. With global competition in the world economy most countries are facing challenges in their domestic economy to be able to compete internationally, in order to survive in a more aggressive and demanding market. In this sense, information, quality, efficiency, and client satisfaction are words and concepts that are discussed constantly in all sectors of the economy. The health care sector has also participated actively in this process. The reforms underway in developed countries have also directly influenced the decisions in Brazil and in other Latin American countries.

Basically, in Brazil and in most of the Latin American countries the public and private health care sectors are separated in terms of their objectives, strategic planning and actions. In most countries the public sector is responsible for delivering a universal health care coverage, but the very limited resources available, the old style of bureaucratic and political administration as well as the continuous changes in their objectives are responsible for a constant decline in the quality of the services delivered. Governments, recognizing the difficulties in changing this scenario, have recently started transferring these responsibilities to the private sector. As a result, in the past 15 years there has been a considerable development of the private health care insurance market. Many national and international health care insurance companies have continuously evaluated opportunities to expand their businesses. Most governments are now officially relying on these services to maintain and expand the delivery of health care to a larger proportion of their population. Also, the sophistication of medical technology and its costs are influencing the patients of the higher social classes (formerly private patients) to buy private health care insurance. Simultaneously, some governments are reevaluating their role in this new scenario much more as regulators and defenders of the public interests. The private market, on the other hand, is becoming increasingly competitive. Information to demonstrate a desirable and acceptable level of health care delivery has been increasingly demanded even by the lay public. Private health care insurance companies, also recognizing the risk they face with the advances of medical technology and with the close obser- 
vation of the health care reform that is occurring in developed countries, have just realized they need to share their risk with the institutions that deliver health care. Although not yet very much oriented about how to do it, there is a sense of identification of partners, education of physicians to reduce their role as the managers of the demand simultaneously to the valuing of evidence-based medicine. The importance of practice guidelines and clinical pathways has been seldom but importantly mentioned as a way of improving the health care delivered without the excessive use of the health technology available. The recognition of this rapidly changing scenario is extremely heterogeneous and varies a lot across government institutions, public and private health care facilities, and insurance companies.

The usual basis of reimbursement of health care providers in both sectors is feefor-service (including negotiated and discounted fee-for-service). There are some initiatives to create some packages that cover the delivery of health care according to specific diagnoses independently of the resources used, but the discussions are in a very preliminary stage. Also, the possibility of having an overall, single fee in the near future has been considered by payers and providers in their strategic planning.
In summary, considering the 3 stages of evolution of the health care market (Provider-driven, in which quality is assumed, Purchaser-driven in which quality is ignored, and Consumer-driven in which quality is demanded), in Latin America the public health care sector is moving very slowly from the Provider-driven to Purchaser-driven stage, while in the private sector there is a trend to move very quickly from the Purchaserdriven to Consumer-driven stage. In the structure of a Purchaser-driven health care market, clinicians and patients should manage care. The purchasers should manage the market and the health care providers should manage quality and cost. This scenario is starting to happen in many leading health care organizations in the most industrialized cities of some Latin American countries. In order to facilitate the shift to a Consumerdriven market, measures of effectiveness and efficiency are needed to direct market share and information is essential for the efficiency of the market and the success of providers. The challenge, therefore, is to be an effective and efficient provider. This definitely requires the establishment of new roles, new relationships and new responsibilities based directly on the development of performance indicators and sophistication of the information infrastructure. 